2020-06

\title{
Invitro avian bioaccessibility of metals adsorbed to microplastic pellets
}

Holmes, Luke

http://hdl.handle.net/10026.1/15426

10.1016/j.envpol.2020.114107

Environmental Pollution

Elsevier BV

All content in PEARL is protected by copyright law. Author manuscripts are made available in accordance with publisher policies. Please cite only the published version using the details provided on the item record or document. In the absence of an open licence (e.g. Creative Commons), permissions for further reuse of content should be sought from the publisher or author. 

pellets

6

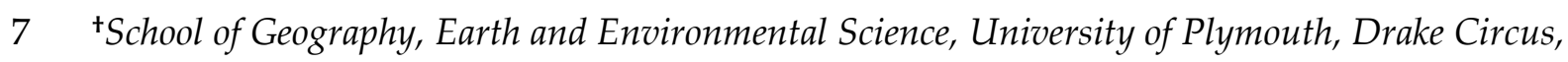

8 Plymouth, UK

9

10 * Address correspondence to luke.holmes@plymouth.ac.uk

11 Accepted 27 January 2020

12 https://doi.org/10.1016/j.envpol.2020.114107

13 
14 Abstract

Microplastics are known to be associated with co-contaminants, but little is understood about the mechanisms by which these chemicals are transferred from ingested plastic to organisms. This study simulates marine avian gastric conditions in vitro to examine the bioaccessibility of authigenic metals $(\mathrm{Fe}, \mathrm{Mn})$ and trace metals $(\mathrm{Co}, \mathrm{Pb})$ that have been acquired by polyethylene microplastic pellets from their environment. Specifically, different categories of pellet were collected from beaches in Cornwall, southwest England, and exposed to an acidified saline solution of pepsin $(\mathrm{pH} \sim 2.5)$ at $40{ }^{\circ} \mathrm{C}$ over a period of $168 \mathrm{~h}$ with extracted metal and residual metal (available to dilute aqua regia) analysed by ICP-MS. For Fe, Mn and Co, kinetic profiles consisted of a relatively rapid initial period of mobilisation followed by a more gradual approach to quasi-equilibrium, with data defined by a diffusion model and median rate constants ranging from about $0.0002\left(\mu \mathrm{g} \mathrm{L}^{-1}\right)^{-1} \mathrm{~h}^{-1}$ for Fe to about $0.8\left(\mu \mathrm{g} \mathrm{L}^{-1}\right)^{-1} \mathrm{~h}^{-1}$ for $\mathrm{Co}$. Mobilisation of $\mathrm{Pb}$ was more complex, with evidence of secondary maxima and re-adsorption of the metal to the progressively modified pellet surface. At the end of the time-courses, maximum total concentrations were $38.9,0.81,0.014$ and $0.10 \mu \mathrm{g} \mathrm{g}^{-1}$ for $\mathrm{Fe}, \mathrm{Mn}, \mathrm{Co}$ and $\mathrm{Pb}$, respectively, with maximum respective percentage bioaccessibilities of around $60,80,50$ and 80 . When compared with toxicity reference values for seabirds, the significance of metals acquired by microplastics from the environment and exposed to avian digestive conditions is deemed to be low, but studies of a wider range of plastics and metal associations (e.g. as additives) are required for a more comprehensive risk assessment.

Capsule: Metals on microplastics that have been acquired from their environment are highly bioaccessible to seabirds but concentrations mobilised are not deemed significant.

Keywords: Bioaccessibility; Metals; Microplastics; Avian; Kinetics; Lead 


\section{Introduction}

39 Plastic debris is a pervasive problem in natural systems with many obvious consequences, such as entanglement of and ingestion by organisms and smothering of benthic habitats.

Over 350 species are known to be impacted by plastic, with the number observed to ingest the material exceeding 180 according to a recent review (Gall and Thompson, 2015). Plastic ingestion is evident at all trophic levels in the marine environment and has been observed in crustaceans, invertebrates, fish, turtles, mammals and seabirds (Laist, 1997; Gregory, 2009). Consequences of ingestion include choking, internal injuries and reduced feeding rate or capacity, which may lead to malnourishment (Ryan 2008; Watts et al., 2015). In addition to physical impacts, there is potential for co-contaminants - chemicals which are bound to the surface or incorporated within the matrix of plastic debris - to be released following ingestion, with possible toxicological effects (Teuten et al., 2009; Tanaka et al., 2015).

Most studies to date have described the accumulation of persistent organic pollutants on microplastic particles (those $<5 \mathrm{~mm}$ in diameter) in the marine environment (Endo et al., 2005; Hirai et al., 2011; Wang et al., 2018), with more recent attention also on the interactions of trace metals with preproduction plastic pellets under a range of environmental scenarios (Holmes et al., 2014; Rochman et al., 2014; Maršić-Lučić et al., 2018). What has been lacking, however, is an assessment of the significance of metals adsorbed to plastic as an exposure route to organisms known to ingest the material.

Ingestion of marine debris by organisms is known to affect 122 species of seabirds (Gall and Thompson, 2015), with some species, like Fulmarus glacialis, observed to ingest plastics in up to $98 \%$ of individuals (van Franeker et al., 2011), with reported mean and maximum quantities of $0.6 \mathrm{~g}$ and $20.6 \mathrm{~g}$, respectively, per individual (van Franeker et al., 2005). 
61 Developing methods to assess the potential impacts of plastic ingestion by wildlife, and in

62 particular by birds, is critical, therefore, since continued exposure to physical and chemical

63 stressors may have effects which have not yet been considered (Koelmans et al., 2014).

64 Although links have been drawn between plastic ingestion and body burdens of metals

65 (Lavers and Bond, 2016) and organic contaminants (Tanaka et al., 2013), there is a lack of

66 empirical data on the mechanisms and magnitude of co-contaminant release from plastic

67 debris under gastric conditions. To this end, the "bioaccessibility" of a co-contaminant is an

68 important factor in quantifying the chemical risk to organisms of the presence of plastic in

69 the environment. Bioaccessibility is defined as the percentage of a total contaminant that is

70 extractable in the gastrointestinal tract and subsequently available for absorption following

71 ingestion (Ruby et al., 1996).

72 This study examines the bioaccessibility of selected metals that had been acquired by

73 microplastic pellets in the environment (and largely through adsorption and precipitation) using a modified, avian version of a standard physiologically based extraction test (PBET).

Aged pellets of different morphologies and colours were used in order to determine whether sample characteristics and degree of weathering have an impact on bioaccessibility under the physical and chemical conditions present within an avian digestive tract. The potential significance of plastic ingestion for metal exposure and accumulation is also considered given that plastics are retained within the avian digestive tract for periods considerably longer than typical retention times for food (Warham, 1996; van Franeker et al., 81 2011).

\section{Materials \& methods}




\subsection{Materials \& reagents}

84 Reagents were supplied by Fisher Scientific (Loughborough, UK) or Sigma Aldrich

85 (Cambridge, UK) and were of trace metal analysis grade, while ICP-MS and ICP-OES

86 calibration standards were sourced from Romil (Cambridge, UK). Prior to use, all equipment was soaked for $>24 \mathrm{~h}$ in a $2 \%$ solution of Decon 90 (an anionic and non-ionic surfactant cleaning solution), rinsed five times with deionised water, and placed directly into a bath containing $1.2 \mathrm{M} \mathrm{HCl}$ for $>48 \mathrm{~h}$. After retrieving equipment from the bath, it was rinsed thoroughly with Milli-Q water (MQW; > 18.2 M $\Omega \mathrm{cm}$ ), dried under laminar flow and stored in a series of clear polyethylene zip-lock bags.

\subsection{Sample collection $\mathcal{E}$ processing}

Pellets were collected with polypropylene tweezers from the strandline of a beach on the south coast of Cornwall, UK $\left(50.339^{\circ} \mathrm{N} 4.239^{\circ} \mathrm{W}\right)$, where the physical characteristics and metal concentrations of microplastics had been previously characterised (Holmes et al., 2012), and stored in polycarbonate bottles. Briefly, pellets ranged in size from approximately

2 to $4 \mathrm{~mm}$ across the broadest dimension, and were typically ovoid or cylindrical in shape.

Pellets were predominantly black, white or off-white (discoloured), with some that were translucent-amber, reflecting significant and visible photo-degradation in the environment.

In the laboratory, samples were stripped of loosely adhered debris by sieving through a 1 mm plastic sieve, which retained pellets but allowed extraneous material to pass through. more firmly adhered particulates. Pellets were then air-dried under laminar flow, divided according to colour and morphology (translucent-white disc, WD, black disc, BD, white 
stored in screw-capped polyethylene pots contained in polyethylene bags until use. Fourier transform infra-red photoacoustic spectroscopy (FTIR-PAS) performed on a subset of all sample types confirmed polyethylene to be the component polymer in all cases.

\subsection{Avian PBET}

Simulated avian gastric conditions were based on previous studies concerned with lead shot bioaccessibility to waterfowl (Kimball and Munir, 1971; Martinez-Haro et al., 2009) and the avian bioaccessibility of lead from mine-impacted soils (Furman et al., 2006) but with modifications in order to more accurately replicate the digestive environment of marine Procellariiformes which commonly ingest microplastic (Colabuono et al., 2009; van Franeker et al., 2011; Avery-Gomm et al., 2012). Thus, incubations were conducted at $40{ }^{\circ} \mathrm{C}$, concentrations of $\mathrm{NaCl}$ and pepsin were $0.1 \mathrm{M}$ and $10 \mathrm{~g} \mathrm{~L}^{-1}$, respectively, and $\mathrm{pH}$ was 2.5 to 2.8 (Turner and Lau, 2016; Turner, 2018).

Synthetic gastric fluid was prepared as a large batch for immediate use in a 1 litre glass volumetric flask by adding $5.844 \mathrm{~g} \mathrm{NaCl}$ and $10 \mathrm{~g}$ pepsin to $\mathrm{MQW}$ whose $\mathrm{pH}$ was amended with $1 \mathrm{M} \mathrm{HCl}$. Forty millilitres of synthetic gastric fluid were added to a series of polypropylene centrifuge tubes which were sealed in clear polyethylene zip-lock bags and placed in a heated water bath. Following a conditioning period, 20 pellets of each category (in triplicate), whose combined weights had been recorded, were added to individual tubes, with controls prepared likewise but with no microplastics added. Samples were then laterally shaken at $100 \mathrm{rpm}$ for a period of one week at $40{ }^{\circ} \mathrm{C}$ and subsamples taken at predetermined time points $(0.25,0.5,1,2,6,12,24,48,102$ and $168 \mathrm{~h})$ throughout the experiment by removing two $1 \mathrm{~mL}$ aliquots $(1 \mathrm{~mL}$ removed and discarded to condition the pipette and $1 \mathrm{~mL}$ to be stored for analysis) and a single pellet in order to maintain a 
reasonably constant pellet-solution ratio. Sample aliquots were immediately diluted fivefold with $2 \% \mathrm{HNO}_{3}$ in $10 \mathrm{ml}$ Sterilin tubes pending analysis. Meanwhile, pellets were rinsed with a few $\mathrm{mL}$ of MQW to remove any gastric solution from the surface and placed as single samples in individual $7 \mathrm{~mL}$ vials where they were air-dried under laminar flow and extracted for residually adsorbed metals using $2.5 \mathrm{~mL}$ of $20 \%$ aqua regia ( $2.3 \mathrm{M} \mathrm{HCl}$ and 3.2 $\mathrm{M} \mathrm{HNO}_{3}$ combined in a ratio of 3:1) (Ashton et al., 2010).

\subsection{Metal analysis}

Metal concentrations in the PBET extracts and aqua regia digests of individual pellets were analysed by inductively coupled plasma-mass spectrometry (Thermo X-Series II ICP-MS, Thermo Elemental, Winsford, UK) with the focus on Fe and Mn, as two indicators of authigenic material, and $\mathrm{Co}$ and $\mathrm{Pb}$, as two elements representative of trace metals which are known to interact with microplastics and exhibit minimal contamination during laboratory analyses (Holmes et al., 2012). Calibrations were performed using five matrixmatched standards and a matrix-matched blank ranging from 0 to $200 \mu \mathrm{g} \mathrm{L}^{-1}$ for $\mathrm{Fe}, 0$ to 100

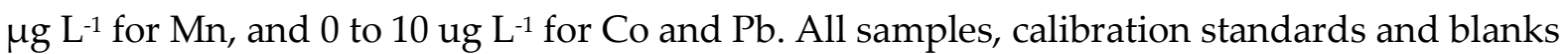
were spiked with ${ }^{115}$ In and ${ }^{193}$ Ir as internal standards to account for any instrumental drift, which was automatically compensated for at the time of analysis. Further checks were made by re-analysing a calibration standard every ten samples. Limits of detection were calculated as three times the standard deviation of calibration blank values.

\section{Results}

\subsection{Total metal concentrations on pellets}

Total concentrations of the four metals that had been acquired from the environment by the polyethylene pellets used in the experiments, $C_{\text {tot, }}$ are shown in Table 1 . Here, concentrations 
are derived from the summed quantities of metal mobilised in the PBET and the total amount of metal remaining on all pellets $(n=20$; and as determined by aqua regia extraction) divided by the combined pellet mass, with the mean and standard deviation for three replicate PBETs of each pellet type given. Mean concentrations are consistent with values determined in previous studies (Ashton et al., 2010; Holmes et al., 2012; Maršić-Lučić et al., 2018), with variations among each pellet type reflecting an inherent heterogeneity in the precise size, surface area and age and degree of weathering of the microplastic substrate.

Table 1: Mean \pm one standard deviation $(n=60)$ of total metal concentrations $\left(C_{\text {tot, }} \mu \mathrm{g} \mathrm{g}^{-1}\right)$ associated with the different types of pellet.

\begin{tabular}{lllll}
\hline Sample & $\mathrm{Fe}$ & $\mathrm{Mn}$ & $\mathrm{Co}$ & $\mathrm{Pb}$ \\
\hline WD & $25.4 \pm 8.15$ & $0.30 \pm 0.14$ & $0.007 \pm 0.002$ & $0.056 \pm 0.028$ \\
BD & $32.1 \pm 8.27$ & $0.48 \pm 0.27$ & $0.008 \pm 0.002$ & $0.060 \pm 0.016$ \\
WRC & $38.9 \pm 0.79$ & $0.81 \pm 0.19$ & $0.014 \pm 0.004$ & $0.095 \pm 0.020$ \\
WSC & $22.5 \pm 2.51$ & $0.23 \pm 0.01$ & $0.005 \pm 0.002$ & $0.037 \pm 0.018$ \\
AD & $28.3 \pm 9.74$ & $0.45 \pm 0.27$ & $0.011 \pm 0.006$ & $0.062 \pm 0.009$ \\
\hline
\end{tabular}

$\mathrm{WD}=$ translucent white disc; $\mathrm{BD}=$ black disc; $\mathrm{WRC}=$ white ridged cylinder; $\mathrm{WSC}=$ white smooth cylinder; $\mathrm{AD}=$ translucent amber disc

\subsection{Metal mobilisation kinetics}

Concentrations of metals released by the avian PBET, $C$, are shown as a function of time in Figures 1 to 4 . For Fe, Mn and Co there is a relatively rapid period of mobilisation followed by a slower approach to quasi-equilibrium; for $\mathrm{Pb}$, however, timed-distributions are more complex with evidence of very rapid mobilisation. For $\mathrm{Pb}$ on all pellet types except WRC equilibrium was reached by the first time point $(0.25 \mathrm{~h})$, with some pellet types exhibiting secondary maxima, suggesting re-adsorption and remobilisation during the PBET incubation. With the exception of $\mathrm{Pb}$, data conformed to a diffusion model of the form defined by Ruby et al. (1992):

$$
1 /\left(C_{\mathrm{e}}-C\right)=1 / C_{\mathrm{e}}+k t
$$


171

172

174 175

where $C_{\mathrm{e}}$ is the concentration mobilised at quasi-equilibrium, $t$ is time and $k$ is a rate constant (units $\left.=\left(\mu g \mathrm{~L}^{-1}\right)^{-1} \mathrm{~h}^{-1}\right)$. Model fits to the data in Figures 1 to 3 were accomplished by using the parameter values in Table 2 , where $C_{\mathrm{e}}$ is the measured concentration at the termination of the experiment and $k$ was derived from the slope of $1 /\left(C_{e}-C\right)-1 / C_{e}$ versus $t$ for the first 6-8 time points of the PBET.

Table 2: Parameter values used to the fit kinetic data (for the pellets shown in Figures 1 - 3) according to equation 1 and, for $\mathrm{Pb}$, quasi-equilibrium concentrations only. Note that the coefficient of determination and number of data points refers to the derivation of $k$.

\begin{tabular}{|c|c|c|c|c|c|c|c|c|c|c|}
\hline \multirow[b]{2}{*}{ Sample } & \multicolumn{3}{|c|}{$\mathrm{Fe}$} & \multicolumn{3}{|c|}{$\mathrm{Mn}$} & \multicolumn{3}{|c|}{ Co } & \multirow{2}{*}{$\begin{array}{r}\mathrm{Pb} \\
C_{\mathrm{e}} \\
\mu \mathrm{g} \mathrm{L}^{-1}\end{array}$} \\
\hline & $\begin{array}{c}C_{\mathrm{e}} \\
\mu \mathrm{g} \mathrm{L}^{-1} \\
\end{array}$ & $\begin{array}{c}k, \\
\left(\mu \mathrm{L} \mathrm{L}^{-1}\right)^{-1} \mathrm{~h}^{-1}\end{array}$ & $r^{2}(n)$ & $\begin{array}{c}C_{\mathrm{e}} \\
\mu \mathrm{g} \mathrm{L}^{-1} \\
\end{array}$ & $\begin{array}{c}k, \\
\left(\mu \mathrm{g} \mathrm{L}^{-1}\right)^{-1} \mathrm{~h}^{-1}\end{array}$ & $r^{2}(n)$ & $\begin{array}{c}C_{\mathrm{e}} \\
\mu \mathrm{g} \mathrm{L}^{-1} \\
\end{array}$ & $\begin{array}{c}k, \\
\left(\mu \mathrm{L} \mathrm{L}^{-1}\right)^{-1} \mathrm{~h}^{-1}\end{array}$ & $r^{2}(n)$ & \\
\hline WD & 226 & 0.00024 & $0.943(7)$ & 3.32 & 0.0263 & $0.609(6)$ & 0.0453 & 2.55 & $0.900(8)$ & 0.624 \\
\hline $\mathrm{BD}$ & 178 & 0.00021 & $0.940(7)$ & 3.53 & 0.0191 & $0.663(7)$ & 0.0353 & 2.88 & $0.226(7)$ & 0.372 \\
\hline WRC & 240 & 0.00020 & $0.949(7)$ & 8.43 & 0.0513 & $0.892(7)$ & 0.0646 & 3.82 & $0.963(8)$ & 1.032 \\
\hline WSC & 210 & 0.00010 & $0.960(7)$ & 2.50 & 0.152 & $0.838(7)$ & 0.0276 & 6.99 & $0.948(8)$ & 0.397 \\
\hline $\mathrm{AD}$ & 216 & 0.00025 & $0.957(7)$ & 5.15 & 0.0441 & $0.917(7)$ & 0.0553 & 1.94 & $0.869(7)$ & 0.568 \\
\hline
\end{tabular}

$\mathrm{WD}=$ translucent white disc; $\mathrm{BD}=$ black disc; $\mathrm{WRC}=$ white ridged cylinder; $\mathrm{WSC}=$ white smooth cylinder; $\mathrm{AD}=$ translucent amber disc

\subsection{Metal bioaccessibilities}

From $C_{\mathrm{e}}$ and $C_{\text {tot, }}$ the percentage of total metal at the end of the one-week PBET that is mobilised and, therefore, bioaccessible, BA, may be determined as follows:

$$
\mathrm{BA}=100 \% \cdot\left(C_{\mathrm{e}} \cdot V / m_{\mathrm{p}}\right) / C_{\text {tot }}
$$

where $V$ and $m$ are the volume of digest $(0.04 \mathrm{~L})$ and mass of pellets $(\sim 0.5 \mathrm{~g})$, respectively, in the experiment. Values of BA are shown for each metal and pellet type in Table 3 and reveal mean percentages that range from about 30 for Co on cylinders and amber discs to $>70$ for $\mathrm{Mn}$ in most cases and $\mathrm{Pb}$ in white discs and white cylinders and relative standard deviations 
among replicates that range from about $1 \%$ to $50 \%$. Despite this wide range in mean values,

bioaccessibility for each metal does not vary significantly between pellet type $(p>0.05$

according to one-way ANOVA) and no single group of pellets consistently carries a greater

or lesser mean bioaccessible fraction of metals than any other. Moreover, there is no clear

relationship between percentage bioaccessibility and total metal concentration between the metals and among the different types of pellet.

Table 3: Percentage bioaccessibilities of metals in each pellet type subject to the avian PBET.

The mean and standard deviation of three replicates is given in each case.

\begin{tabular}{lllll}
\hline Sample & $\mathrm{Fe}$ & $\mathrm{Mn}$ & $\mathrm{Co}$ & $\mathrm{Pb}$ \\
\hline WD & $62.6 \pm 8.82$ & $77.7 \pm 20.6$ & $48.7 \pm 11.6$ & $77.7 \pm 7.22$ \\
BD & $55.4 \pm 3.92$ & $73.6 \pm 16.1$ & $42.0 \pm 2.06$ & $61.2 \pm 9.89$ \\
WRC & $43.3 \pm 0.88$ & $73.1 \pm 16.7$ & $32.4 \pm 1.93$ & $70.2 \pm 20.6$ \\
WSC & $60.2 \pm 6.73$ & $69.9 \pm 4.07$ & $34.6 \pm 8.53$ & $69.9 \pm 17.0$ \\
AD & $52.7 \pm 11.1$ & $78.4 \pm 11.1$ & $33.9 \pm 18.8$ & $62.9 \pm 9.80$ \\
\hline
\end{tabular}

197

\section{Discussion}

Given that oxides of Fe and Mn are important and ubiquitous authigenic host phases for many particulate contaminants, including trace metals, in the aquatic environment (Muller et al., 2002; Manceau et al., 2007), the presence of Fe and Mn on the pellets reflects their accumulation from the environment, principally through adsorption and precipitation on to the plastic surface. The Fe to Mn ratio on a mass (and molar) basis averages about 60 for all samples measured. This is similar to ratios reported for Fe and $\mathrm{Mn}$ available to $1 \mathrm{M} \mathrm{HCl}$ in suspended particulate matter sampled from the coastal regions of the southern North Sea

205 (Turner and Millward, 2000), suggesting that the accumulation of oxidic phases on plastics and natural solids proceeds via similar mechanisms and/or in a similar stoichiometry. 
The ready mobilisation of Fe and Mn from the plastic pellets subject to an avian PBET

reflects the progressive dissolution of authigenic phases under the acidic and enzymatic conditions of the digestive fluid that is modelled using a simple diffusion-based equation.

210 Trace metal contaminants are likely to be associated with these authigenic phases through

211 adsorption and co-precipitation, as well as with organic phases, including biofilms, that

212 have accumulated in situ (Richard et al., 2019). The mobilisation of trace metals under the

213 simulated avian digestive conditions is predicted to be controlled by desorption from the

214 surfaces of these phases, as well as from any adsorption sites on the plastic itself engendered

215 by photo-oxidation (Rochman et al., 2014), in addition to mechanisms responsible for host

216 phase dissolution. Accordingly, the kinetic profiles exhibited by some trace metals,

217 exemplified herein by $\mathrm{Co}$, are similar to those of Fe and Mn, suggesting a significant

218 association with oxidic phases. For other trace metals, however, such as $\mathrm{Pb}$, mobilisation

219 kinetics are more complex, with very rapid release within the first few hours of exposure and evidence of subsequent secondary maxima over the subsequent duration of the timecourse. This may reflect an association with other (e.g. biogenic and proteinaceous) phases that are denuded by the gastric enzyme (pepsin) or the redistribution (e.g. re-adsorption) of the metal on the surface as it is progressively modified under the chemical conditions of the PBET.

Typical residence times for natural food items in the gizzard of seabirds like F. glacialis are on the order of a few hours (Warham, 1996). However, since plastic particles are more slowly processed than natural ingesta (with the exception of hard parts such as fish otoliths or squid beaks), they will be retained in the digestive tract for longer periods, with estimates of residence times ranging from days to weeks (van Franeker et al., 2011). Consequently, it is 
predicted that the mobilisation of metals associated with microplastics through adsorption

231 to the plastic and association with authigenic surface phases will readily reach quasiequilibrium within the marine avian digestive system.

233 In order to estimate the likely quantity of metal conveyed to avian species via ingestion

234 of microplastic debris that is bioaccessible, but not necessarily bioavailable and able to

235 pass the gut epithelium, concentration and bioaccessibility data derived above were combined with literature values for typical plastic body burdens:

$$
I_{\mathrm{p}}=m_{\mathrm{p}} \cdot C_{\text {tot }} \cdot \mathrm{BA} / 100 \%
$$

237 where $I_{\mathrm{p}}$ is the quantity of metal mobilised in the digestive environment from ingested 238 plastic $(\mu \mathrm{g})$ and $m_{\mathrm{p}}$ is the mass of ingested plastic $(\mathrm{g})$.

239 Mean abundances of ingested plastic in F. glacialis have been recorded at $0.6 \mathrm{~g}$, but values 240 are highly variable with a maximum of $20.6 \mathrm{~g}$ reported by van Franeker et al. (2005). Here, 241 therefore, both mean and maximum values are used to calculate $I_{\mathrm{p}}{ }^{\text {mean }}$ and $I_{\mathrm{p}}{ }^{\text {max }}$, respectively.

242 Results shown in Table 4 are based on the highest mean bioaccessibilities and total metal 243 concentrations and represent worst case scenarios, with the maximum amount of the most 244 toxic metal, $\mathrm{Pb}$, mobilised via ingested microplastic around $1.7 \mu$ g over the time period by 245 which $20.6 \mathrm{~g}$ is processed by the bird.

246 Table 4: Quantities of metals (in $\mu \mathrm{g})$ accessible to a seabird ingesting $0.6 \mathrm{~g}\left(\mathrm{I}_{\mathrm{p}}{ }^{\text {mean }}\right)$ or $20.6 \mathrm{~g}$ $247\left(I_{\mathrm{p}}^{\max }\right)$ of plastic calculated from the data in Tables 1 and 3 and using equation 3.

\begin{tabular}{lcccc}
\hline & Fe & Mn & Co & Pb \\
\hline$I_{\mathrm{p}}$ mean & 14.6 & 0.38 & 0.004 & 0.05 \\
$I_{\mathrm{p}}$ max & 501.6 & 13.1 & 0.14 & 1.65 \\
\hline
\end{tabular}


248 In order to evaluate the risk from metals acquired by plastics in the environment through

249 ingestion, results above were used to estimate the mass of material required to be ingested

250 before adverse effects are possible $\left(m_{\mathrm{p}}\right.$ adv, $\left.\mathrm{g}\right)$, assuming that all metal mobilised from ingested

251 plastic is available for accumulation:

252

$$
m_{\mathrm{p}}^{\mathrm{adv}}=\left(\mathrm{TRV} \cdot m_{\mathrm{bird}}\right) /\left(C_{\mathrm{tot}} \cdot \mathrm{BA} / 100 \%\right)
$$

Here, TRV represents a toxicity reference value for avian species and is $179,7.61$ and $1.63 \mu \mathrm{g}$

$\mathrm{g}^{-1}$ body weight for $\mathrm{Mn}, \mathrm{Co}$ and $\mathrm{Pb}$, respectively (Sample et al., 2014). For a bird of $0.75 \mathrm{~kg}$,

$m_{\mathrm{p}}^{\text {adv }}$ is computed to be $130 \mathrm{~kg}$ for $\mathrm{Mn}$ and $200 \mathrm{~kg}$ for Co based on the highest total

Clearly, microplastic masses of this magnitude are not likely to be ingested over the entire

lifespan of a $0.75 \mathrm{~kg}$ seabird and, on this basis, and at least with respect to metals on an

individual basis, toxic effects are predicted to be negligible.

260 However, it must be borne in mind that pellets represent only one form of microplastic

debris in the environment, and of greater concern from a toxicological perspective are legacy

262 microplastics that may contain significant quantities of metals in the matrix in the form of additives or reaction residues. For example, recent studies of beached foamed plastics and

264 thermoplastic fragments reveal $\mathrm{Pb}$ concentrations that are five orders of magnitude higher than those reported here (Turner and Lau, 2016; Turner, 2018), with bioaccessibilities of just

$2661 \%$ resulting in bioaccessible concentrations thousands of times greater than those acquired

267 from the environment by microplastic pellets. For instance, applying equation 4 to plastic containing $10000 \mu \mathrm{g} \mathrm{g}^{-1}$ of $\mathrm{Pb}$ added as a pigment or a stabiliser and which is $1 \%$ 
bioaccessible results in an ingested mass having potentially adverse effects due to this metal

270 of just $12 \mathrm{~g}$.

271 For a more accurate risk assessment, multiple types of plastic of different sizes would

272 have to be incorporated into a model similar to that defined by equation 4 . Thus,

273 polymers of different composition and crystallinity may have different affinities for

274 dissolved metals while there is likely to be an inverse dependence of metal adsorption on particle size; of particular significance regarding the latter effect are nanoplastics whose role in marine environments and on organisms of lower trophic level than birds is currently under investigation (Al-Sid-Cheikh et al., 2018; Ferreira et al., 2019). Moreover, since microplastics may simultaneously present both chemical and physical impacts to organisms upon ingestion, in vitro assessment of contaminant release should be incorporated into an environmentally-relevant multi-stressor exposure approach to evaluate the combined hazards of microplastics.

\section{Conclusions}

Authigenic $(\mathrm{Fe}, \mathrm{Mn})$ and co-contaminant $(\mathrm{Co}, \mathrm{Pb})$ metals acquired by polyethylene microplastic pellets from the environment are readily mobilised by an avian PBET and, with the exception of $\mathrm{Pb}$, kinetic data conform to a simple diffusion model. Despite such mobilisation, concentrations themselves are insufficient to cause any adverse effects on seabirds that ingest plastic. However, when other types of plastic are considered, such as those with metallic functional additives, the risk may be significant. Future studies should address the different associations of metals with a greater diversity of microplastics in order to formulate a more generic risk assessment for ingested metals. 
293 We are grateful to Dr Andy Fisher and Mr Andrew Arnold, UoP, for technical support 294 throughout the study. The project was funded by the Marine Institute of UoP.

295

296

298

299

300

301

302

303

304

305

306

307

Al-Sid-Cheikh, M., Rowland, S.J., Stevenson, K., Rouleau, C., Henry, T.B., Thompson, R.C. 2018. Uptake, whole-body distribution, and depuration of nanoplastics by the scallop Pecten maximus at environmentally realistic concentrations. Environ. Sci. Technol. 52: 14480-14486.

Ashton, K., Holmes, L.A., Turner, A. 2010. Association of metals with plastic production pellets in the marine environment. Mar. Pollut. Bull. 60: 20502055.

Avery-Gomm, S., O’Hara, P.D., Kleine, L., Bowes, V., Wilson, L.K., Barry, K.L. 2012. Northern fulmars as biological monitors of trends of plastic pollution in the eastern North Pacific. Mar. Pollut. Bull. 64: 1776-1781.

Colabuono, F.I., Barquete, V., Domingues, B.S., Montone, R.C. 2009. Plastic ingestion by Procellariiformes in Southern Brazil. Mar. Pollut. Bull. 58: 93-96.

Endo, S., Takizawa, R., Okuda, K., Takada, H., Chiba, K., Kanehiro, H., Ogi, H., Yamashita, R., Date, T. 2005. Concentration of polychlorinated biphenyls (PCBs) in beached resin pellets: Variability among individual particles and regional differences. Mar. Pollut. Bull. 50: 1103-1114.

Ferreira, I., Venancio, C., Lopes, I., Oliveira, M., 2019. Nanoplastics and marine organisms: What has been studied? Environ. Toxicol. Pharmacol. 67: 1-7. 

lead bioaccessibility to waterfowl in mine-impacted soils. J. Environ. Qual. 35: $450-458$.

Gall, S. Thompson, R.C., 2015. The impacts of debris on marine life. Mar. Pollut. Bull. 92: 170-179.

Gregory, M.R. 2009. Environmental implications of plastic debris in marine settingsentanglement, ingestion, smothering, hangers-on, hitch-hiking and alien invasions. Phil. Trans. R. Soc. B 364: 2013-2025.

Hirai, H., Takada, H., Ogata, Y., Yamashita, R., Mizukawa, K., Saha, M., Kwan, C., Moore, C., Gray, H., Laursen, D., Zettler, E.R., Farrington, J.W., Reddy, C.M., Peacock, E.E., Ward, M.W. 2011. Organic micropollutants in marine plastics debris from the open ocean and remote and urban beaches. Mar. Pollut. Bull. 62: 1683-1692.

Holmes, L.A., Turner, A., Thompson, R.C. 2012. Adsorption of trace metals to plastic resin pellets in the marine environment. Environ. Pollut. 160: 42-48.

Holmes, L.A., Turner, A., Thompson, R.C. 2014. Interactions between trace metals and plastic production pellets under estuarine conditions. Mar. Chem. 167: $25-32$.

Kimball, W.H., Munir, Z.A. 1971. Corrosion of lead shot in a simulated waterfowl gizzard. J. Wildlife Manage. 35: 360-365.

Koelmans, A.A., Gouin, T., Thompson, R.C., Wallace, N., Arthur, C. 2014. Plastics in the marine environment. Environ. Toxicol. Chem. 33: 5-10. 
Laist, D.W. 1997. Impacts of marine debris: entanglement of marine life in marine debris including a comprehensive list of species with entanglement and ingestion records. In Coe JM. Rogers DB. (Eds.) Marine debris, sources, impacts, and solutions. Springer-Verlag, New York, 99-139.

Lavers, J.L., Bond, A.L., 2016. Ingested plastic as a route for trace metals in Laysan Albatross (Phoebastria immutabilis) and Bonin Petrel (Pterodroma hypoleuca) from Midway Atoll. Mar. Poll. Bull. 110: 493-500.

Manceau, A., Lanson, M., Geoffroy, N., 2007. Natural speciation of Ni, Zn, Ba, and As in ferromanganese coatings on quartz using X-ray fluorescence, absorption, and diffraction. Geochim. Cosmochim. Acta 71: 95-128.

Maršić-Lučić, J., Lušić, J., Tutman, P., Bojanić Varezić, D., Šiljić, J., Pribudić, J., 2018. Levels of trace metals on microplastic particles in beach sediments of the island of Vis, Adriatic Sea, Croatia. Marine Pollution Bulletin 137: 231-236.

Martinez-Haro, M., Taggart, M.A., Green, A.J., Mateo, R. 2009. Avian digestive tract simulation to study the effect of grit geochemistry and food on $\mathrm{Pb}$ shot bioaccessibility. Environ. Sci. Technol. 43: 9480-9486.

Muller, B., Granina, L., Schaller, T., Ulrich, A., Wehrli, B., 2002. P, As, Sh, Mo, and other elements in sedimentary Fe/Mn layers of Lake Baikal. Environ. Sci. Technol. 36: 411-420.

Richard, H., Carpenter, E.J., Komada, T., Palmer, P.T., Rochman, C.M., 2019. Biofilm facilitates metal accumulation onto microplastics in estuarine waters. Sci. Total Environ. 683: 600-608. 
Rochman, C.M., Hentschel, B.T., Teh, S.J. 2014. Long-Term Sorption of Metals Is Similar among Plastic Types: Implications for Plastic Debris in Aquatic Environments. PLoS ONE 9: e85433.

Ruby, M.V., Davis, A., Kempton, J.H., Drexler, J.W., Bergstrom, P.D. 1992. Lead bioavailability: dissolution kinetics under simulated gastric conditions. Environ. Sci. Technol. 26: 1242-1248.

Ruby, M.V., Davis, A., Schoof, R., Eberle, S., Sellstone, C.M. 1996. Estimation of lead and arsenic bioavailability using a physiologically based extraction test. Environ. Sci. Technol. 30: 422-430.

Ryan, P.G. 2008. Seabirds indicate changes in the composition of plastic litter in the Atlantic and south-western Indian Oceans. Mar. Pollut. Bull. 56: 1406-1409. Sample, B.E., Fairbrother, A., Kaiser, A., Law, S., Adams, B. 2014. Sensitivity of ecological screening levels for metals to exposure model parameterization and toxicity reference values. Environ. Toxicol. Chem. 33: 2386-2398.

Tanaka, K., Takada, H., Yamashita, R., Mizukawa, K., Fukuwaka, M., Watanuki, Y. 2013. Accumulation of plastic-derived chemicals in tissues of seabirds ingesting marine plastics. Mar. Pollut. Bull. 69: 219-222.

Tanaka, K., Takada, H., Yamashita, R., Mizukawa, K., Fukuwaka, M.A., Watanuki, Y., 2015. Facilitated leaching of additive-derived PBDEs from plastic by seabirds' stomach oil and accumulation in tissues. Environ. Sci. Technol. 49: 11799-11807. 
Teuten, E.L., Saquing, J.M., Knappe, D.R.U., Barlaz, M.A., Jonsson, S., Björn, A, Rowland, S.J., Thompson, R.C., Galloway, T.S., Yamashita, R., Ochi, D., Watanuki, Y., Moore, C., Viet, P.H., Tana, T.S., Prudente, M., Boonyatumanond, R., Zakaria, M.P., Akkhavong, K., Ogata, Y., Hirai, H., Iwasa, S., Mizukawa, K., Hagino, Y., Imamura, A., Saha, M., Takada, H. 2009. Transport and release of chemicals from plastics to the environment and to wildlife. Phil. Trans. R. Soc. B 364: 2027-2045.

Turner, A., Lau, K.S., 2016. Elemental concentrations and bioaccessibilities in beached plastic foam litter, with particular reference to lead in polyurethane. Mar. Poll. Bull. 112: 265-270.

Turner, A., Millward, G.E., 2000. Particle Dynamics and Trace Metal Reactivity in Estuarine Plumes. Estuar. Coastal Shelf Sci. 50: 761-774.

Turner, A., 2018 Mobilisation kinetics of hazardous elements in marine plastics subject to an avian physiologically-based extraction test. Environ. Pollut. 236: 1020-1026.

van Franeker, J.A., Heubeck, M., Fairclough, K., Turner, D.M., Grantham, M., Stienen, E.W.M., Guse, N., Pedersen, J., Olsen, K.O., Andersson, P.J., Olsen, B. 2005. Save the North Sea Fulmar study 2002-2004: a regional pilot project for the Fulmar-Litter-EcoQO in the OSPAR area. Wageningen, Alterra, Alterra-rapport 1162.

van Franeker, J.A., Blaize, C., Danielsen, J., Fairclough, K., Gollan, J., Guse, N., Hansen, P.L., Heubeck, M., Jensen, J.K., Le Guillou, G., Olsen, B., Olsen, K.O., Pedersen, J., Stienen, E.W.M., Turner, D.M. 2011. Monitoring plastic 

ingestion by the northern fulmar Fulmarus glacialis in the North Sea. Environ. Pollut. 159: 2609-2615.

404 Wang, Z., Chen, M.L., Zhang, L.W., Wang, K., Yu, X.B., Zheng, Z.M., Zheng, R.Y., 2018. Sorption behaviors of phenanthrene on the microplastics identified in a mariculture farm in Xiangshan Bay, southeastern China. Sci. Total Environ. 628-629: 1617-1626.

Warham, J. 1996. The behaviour, population biology and physiology of the petrels. Academic Press, London. microfibers by the crab Carcinus maenas and its effect on food consumption and energy balance. Environ. Sci. Technol. 49: 14597-14604. 
412 Figure 1: Mobilisation kinetics of Fe from the five types of microplastic pellets, defined in Table 1. Error bars represent the standard

413 deviation about the mean of three replicate incubations, and solid lines represent fits according to equation 1 and constants given in Table

414 2. WD: translucent white disc; BD: black disc; WRC: white ridged cylinder; WSC: white smooth cylinder; AD: translucent amber disc.
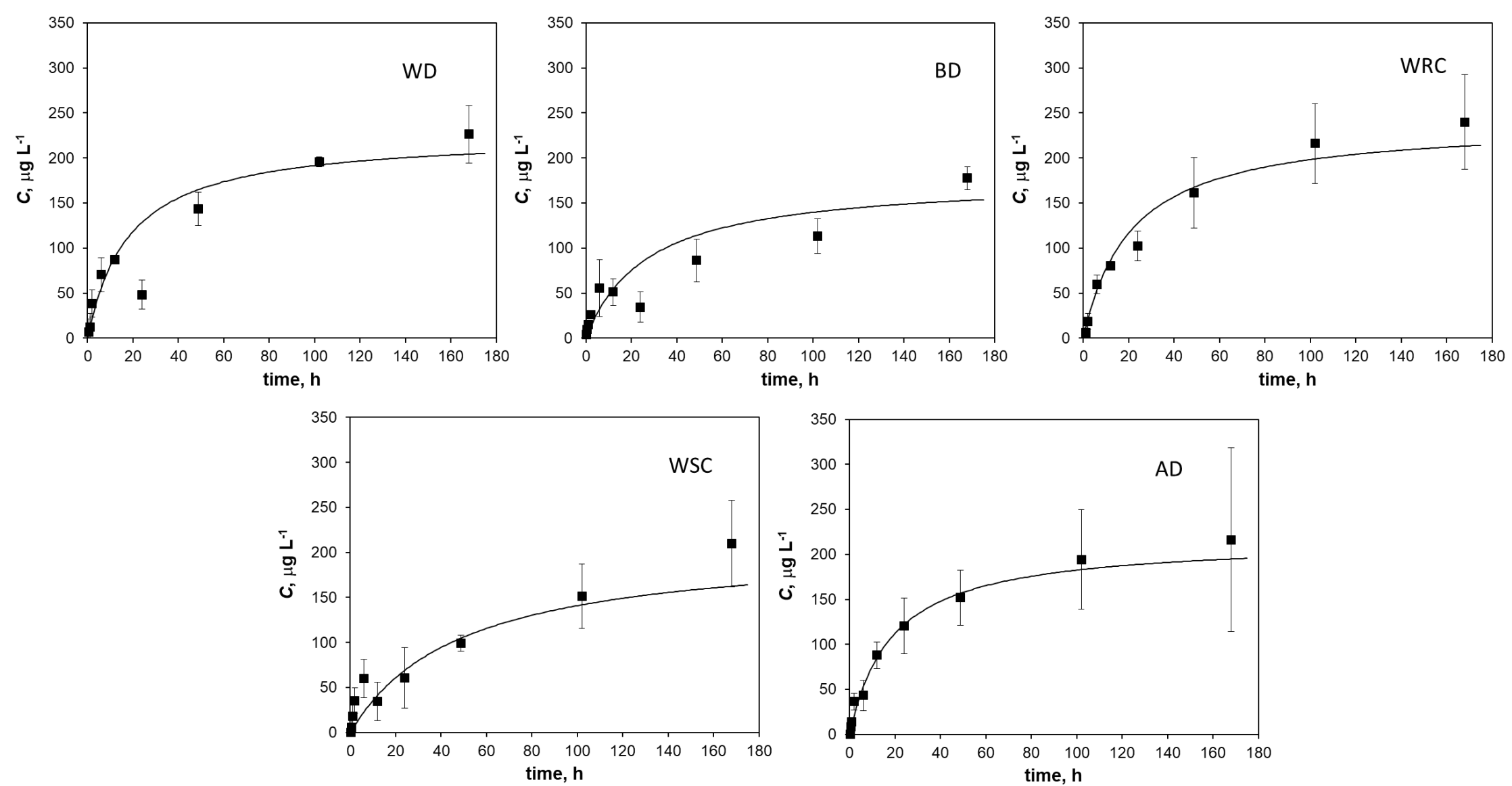
Figure 2: Mobilisation kinetics of Mn from the five types of microplastic pellets, defined in Table 1. Error bars represent the standard

417 deviation about the mean of three replicate incubations, and solid lines represent fits according to equation 1 and constants given in Table

418 2. WD: translucent white disc; BD: black disc; WRC: white ridged cylinder; WSC: white smooth cylinder; AD: translucent amber disc.
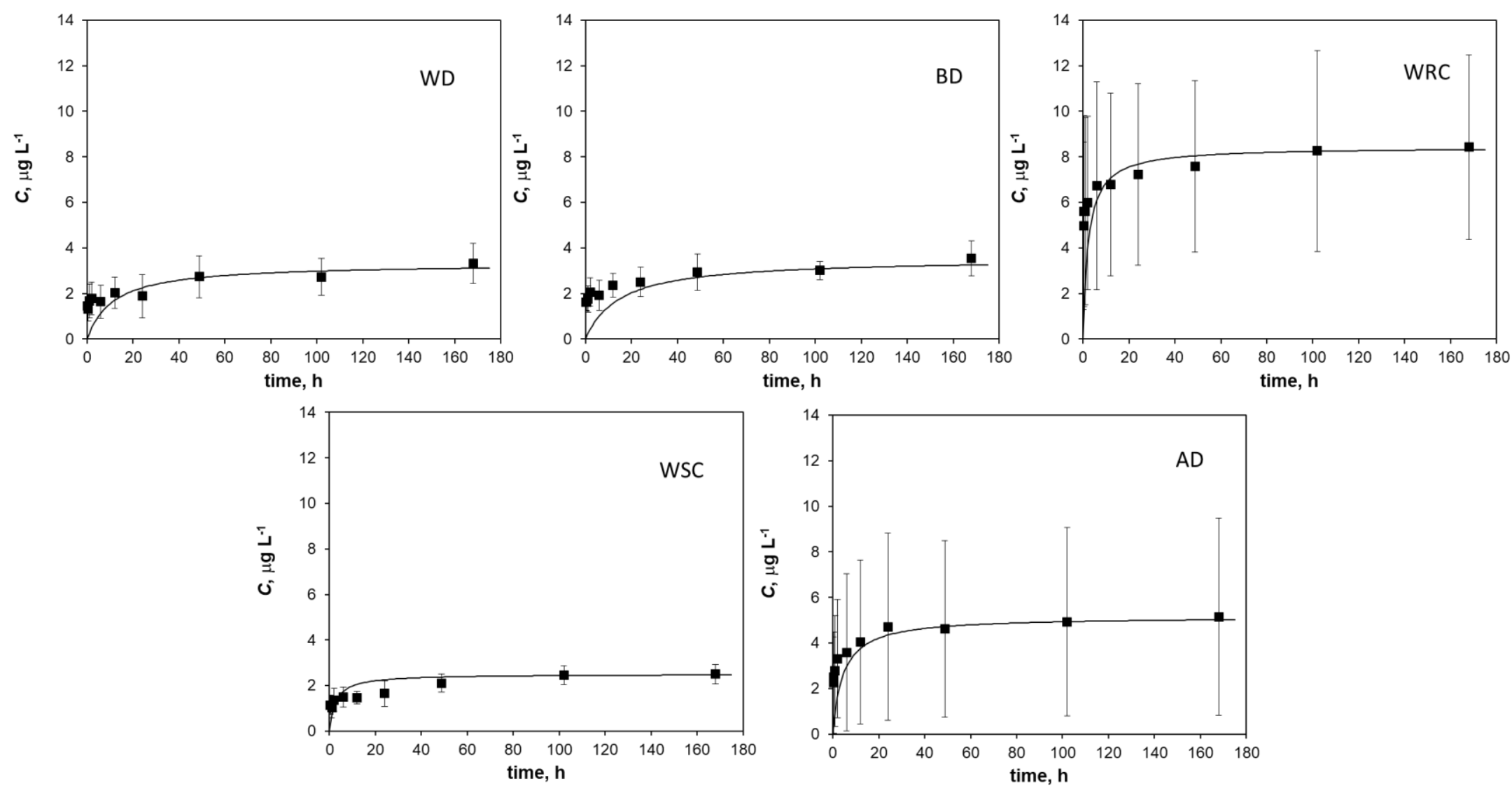
Figure 3: Mobilisation kinetics of Co from the five types of microplastic pellets, defined in Table 1. Error bars represent the standard

421 deviation about the mean of three replicate incubations, and solid lines represent fits according to equation 1 and constants given in Table

2. WD: translucent white disc; BD: black disc; WRC: white ridged cylinder; WSC: white smooth cylinder; AD: translucent amber disc.
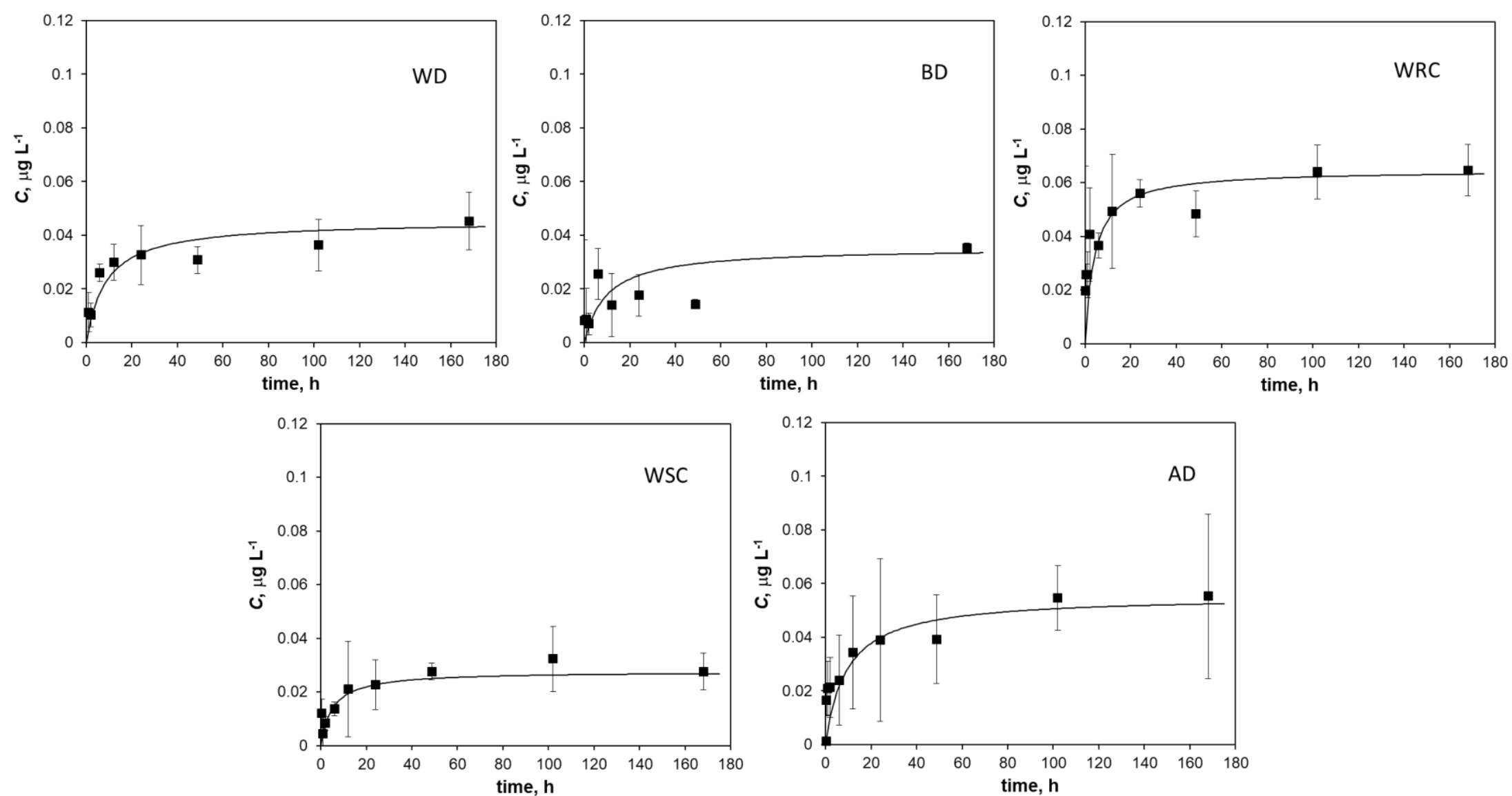
Figure 4: Mobilisation kinetics of $\mathrm{Pb}$ from the five types of microplastic pellets, defined in Table 1. Error bars represent the standard
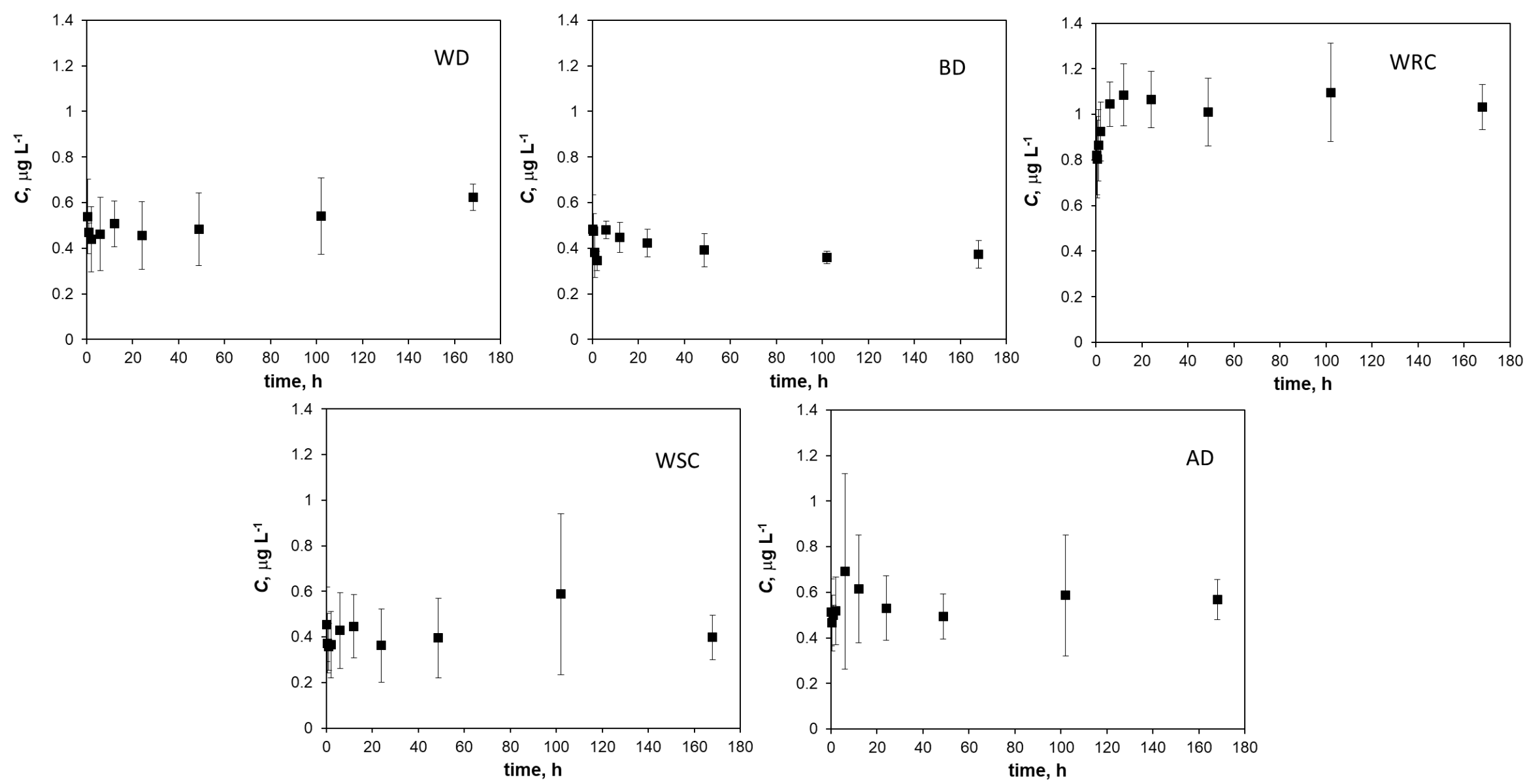